20. Specht, T. thesis, Duke Univ. (1987)

21. Flannery, J. thesis, Duke Univ. (1988)

22. Specht, T. \& Rosendahl, B. R. in African Rifting (eds Rosendahl, B. R., Rogers, J. W. \& Rach, N. M.) (Pergamon, London, in the press).

23. Bally, A. W. Phil. Trans. R. Soc. Lond. 305, 325-338 (1982)

24. Anhaeusser, C. R. et al. Bull. geol. Soc. Am. 80, 2175-2200 (1969).

25. Daly M C Trans R Soc Lond A317, 111 128 119861

26. Daly M C Chorowicz. \& \& Fairbead J. D. lnversis. Tectonics (Geol Soc Lond spec. Publn, in the press).

27. Chorowicz, J. \& Mukoni, M. N. B. Musée royale de l'Afrique centrale, Tervuren, Belgique 143-167 (Dept Geol. Miner., Rapport annuele, 1979).

28. Chorowicz, J. \& Mukoni, M. N. B. Comptes Rendus de PAcademie du Science à Paris Ser D 220, 1245-1247 (1980).

29. Kazmin, V. Geodynamic Evolution of the Afro-Arabian Rift System Accadmia Nazionale dei Lincei, Atti dei Convegni Lincei 47, 65-73 (Rome, 1980).

30. Sykes, L. Bull, seismol, Soc. Am. 60, 1749-1752 (1970).

31. Faithead, J. D. \& Girdler, R. W. Geophys. J. R. astr. Soc. 24, 271-301 (1971)

32. Maasha, N. \& Molnar, P. J. genphys Res. 77, 5731-5743 (1972)

33. Scholz, C. H. Koczynski, T. A. \& Hutchins, D. G. Geophys, J. R. astr. Soc. 44, 135-144 (1976)

34. Fairhead, J. D. \& Henderson, N. B. Tectonophysics 41, 19-26 (1977).

35. Fairhead, J. D. \& Stuart, G. W. Continental and Oceanic Rifts Am. geophys. Un. Geodyn Ser. 8. 41-61 (1982)

36. Shudofsky, G. N. Geophys. J. R. astr. Soc, 83, 563-614 (1985).

37. Wohlenberg, J. Tectonophysics 8, 567-577 (1969).

38. Chorowicz, J., Mukanti, N. \& Pottier, Y. C. R. somm. soc. geol. 5-6, 231-234 (1979).

39. Chorowicz, J. Ancient Rifts and Troughs Bull. Centres Rech. Explor.-Prod. Elf-Aquitaine 7, 155-162 (1982).

40. Wheeler, W. \& Karson, J. in African Rifting (eds Rosendahl, B. R., Rogers, J. W. \& Rach, N. M.) (Pergamon, London, in the press).

41. UNESCO International tectonic Map of Africa (UNESCO Earth Sciences, 1968).

42. UNESCO Tectonics of Africa (UNESCO Earth Sciences, 1971).

43. Bloomfield, K. Geological Map of Malawi (Edward Stanford, 1966)

44. McConnell, R. B. Geodynamic Evoluation of the Afro-Arabian Rift System 47, 35-43 (Academia Nazionale die Lincei, Atti dei convegni Lincei, Rome, 1980).

\section{Facultative viviparity in a thrips}

\section{Bernard J. Crespi*}

Museum of Zoology and Department of Biology, University of Michigan, Ann Arbor, Michigan 48109-1079, USA

The absence of species that show facultative variation in reproductive mode within populations ${ }^{1-4}$ has thus far severely hindered study of the selective pressures associated with oviparity and viviparity. Here I report that females of the mycophagous thrips Elaphrothrips tuberculatus (Insecta: Thysanoptera) are facultatively viviparous and produce male offspring by viviparity and female offspring by oviparity. Individual females can switch between the two reproductive modes. Females produce fewer offspring when viviparous than when oviparous, but the survivorship of viviparous offspring is sufficiently high that the average number of pupal offspring produced by females in each mode is similar. Facultatively viviparous thrips provide the first experimental systems for analysing the behavioural, ecological and physiological causes of variation in reproductive mode.

Elaphrothrips tuberculatus is a winged thrips about $5 \mathrm{~mm}$ long that lives on clusters of hanging dead oak leaves and feeds on fungal spores ${ }^{5,6}$. In southern Michigan, it overwinters as adults of both sexes in leaf litter, emerges in mid-April to mid-May, and undergoes two generations per year. Observations of breeding adults show that some females deposit eggs one at a time, over a 1-3-week period, onto an egg mass which they defend against potential egg predators ${ }^{7}$. By contrast, other females do not lay eggs, although they are gravid during any given breeding period. Dissection of gravid females demonstrates that oviparous females contain four ovarioles with each ovariole comprising enlarging, undeveloped oocytes arranged linearly. Viviparous females contain two clusters of embryos in increasingly advanced stages of development distally, such that fully gravid females contain one or several fully developed first-instar larvae. Two lines of evidence indicate that this variation among breeding females represents a reproductive dimorphism rather

* Present address: School of Biological Science, PO Box 1, University of New South Wales, Kensington, New South Wales 2033, Australia. than stages of egg retention: first, the ovaries of more than 738 dissected females were of one or the other type, and second, gravid females isolated in Petri dishes deposit either a mass of undeveloped eggs that they guard $(N=20)$ or several first-instar larvae (with no trace of chorion visible) $(N=53)$. Larvae or eggs are often deposited within $24 \mathrm{~h}$ of isolation.

If reproductive mode is under facultative female control, then individual females may be capable of switching between oviparity and viviparity. E. tuberculatus females normally reproduce once during the one-month spring generation, but the summer generation lasts for about two months, which allows sufficient time for multiple bouts of reproduction ${ }^{6}$. Allowing females to breed individually in summer on dead oak leaves in nylon bags so as to record their reproductive mode (by noting the presence of egg masses and the presence and sex of offspring ${ }^{6,8}$ ) showed that about one-third of females switched reproductive mode in 1986 (21 both modes, 15 viviparous, 20 oviparous) and 1987 (20 both modes, 19 viviparous, 12 oviparous). E. tuberculatus is apparently the only animal species known in which individual females are capable of switching between oviparity and viviparity.

Because reproductive mode is under facultative female control in this species, variation in mode may be associated with variation in measurable aspects of females and their environments. The body sizes (lengths of the fore-femora) of viviparous and oviparous females did not differ during the spring generation, but during the summer generation viviparous females were substantially larger than oviparous females?. To determine whether or not aspects of seasonality affect female reproductive mode, I allowed individual females from both the spring and summer generation to breed on both spring- and summer-generation dead oak leaves (summer leaves have died within the past few months, whereas spring leaves died in the preceding year). The only treatment in which females were viviparous (5 of 14) was summer females on summer leaves; no females were viviparous in the spring females/spring leaves treatment $(0$ of $15)$, the spring females/summer leaves treatment ( 0 of 13 ), or the summer females/spring leaves treatment ( 0 of 14) $(G=15.4$, $P<0.005)$. These data suggest that a proximate cause of viviparous reproduction involves interaction between a female's generation and the generation of the leaves that she inhabits.

All thrips are believed to have a haplodiploid genetic system, such that haploid males develop parthenogenetically, and diploid females develop from fertilized eggs ${ }^{10,11}$. Sexing of firstinstar larvae ${ }^{6,8}$ showed that, in E. tuberculatus, all of 1,051 newly hatched larvae from eggs laid by 42 females were female, and all of 202 larvae produced by 32 viviparous females were male. These data indicate that mode of reproduction is invariably associated with offspring sex. But sperm were seen clearly in the spermathecae of $134(87 \%)$ of 154 dissected viviparous females.

Because females produce single-sex broods, individual breeding females can be considered as units of investment in one sex or the other ${ }^{6}$. Thus, if females are equal in resources available for breeding, then frequency-dependent selection on sex allocation $^{12}$ should favour a population-wide proportion viviparity (that is, a sex-allocation ratio) of $50 \%$. In E. tuberculatus, deviations from $50 \%$ viviparity (Table 1 ) may be caused by a sex difference in the degree of competition among siblings between spring and summer ${ }^{6}$ and partial bivoltinism with variation between generations in the reproductive value of the two sexes ${ }^{13}$. Moreover, if the large size of viviparous females relative to oviparous females in summer represents a difference in resources available for investment, then the summer sex-allocation ratio is more male biassed than it would appear to be from the proportion of females in each reproductive mode.

The association between offspring sex and reproductive mode in E. tuberculatus allows testing of a central hypothesis concerning the evolution of viviparity: that viviparous females should produce fewer offspring than oviparous females, but that these 
Table 1 Fecundity of oviparous and viviparous females and the relative survivorship of their offspring

\begin{tabular}{|c|c|c|c|c|c|}
\hline Season & Pupal sex ratio & Mode & Percentage females in mode & Average fecundity & Relative survivorship \\
\hline \multirow[t]{2}{*}{ Spring } & 0.19 & Viviparity & 0.25 & 21.5 & 1.4 \\
\hline & & Oviparity & 0.75 & 43.7 & 1.0 \\
\hline Summer & & Oviparity & 0.45 & 26.1 & 1.0 \\
\hline
\end{tabular}

Within each sex, the number of pupae present at the end of a generation should be equal to the number of females in the appropriate reproductive mode during that breeding period, multiplied by their average fecundity, multiplied by the survivorship of their offspring from egg laying or larviposition to the pupal stage. Pupal sex ratio was calculated by collecting pupae during the spring and summer generations, allowing them to become adult, and sexing the adults (see refs 6,9). The spring pupal sex ratio is the average for $1984(0.19$ male, $N=9,709)$, 1985 $(0.16$ male, $N=6,617)$, and $1986(0.21$ male, $N=3,158)$, and the summer pupal sex ratio is the average for $1985(0.69 \mathrm{male}, N=483)$ and $1986(0.46$ male, $N=1,399$ ) (ref. 6). The percentage of females in each mode was determined by dissecting females and inspecting their ovaries (see refs 6,9$)$; the percentage for spring is the average for 1986 ( 0.26 viviparous, $N=449)$ and $1987(0.24$ viviparous, $N=902)$, and the percentage for summer is data from $1986(N=645)$. Oviparous female fecundity was measured in spring by counting the number of eggs in complete clutches and taking the average for $1985(39.5 \pm 8.7, N=127), 1986(46.6 \pm 9.4, N=121)$, and $1987(44.9 \pm 9.9, N=145)$ (refs 6,7$)$. In summer, oviparous female fecundity was measured by counting the number of eggs in completed and abandoned egg masses $(26.1 \pm 11.4, N=222$, data from 1986) (refs 6 , 7). In spring, viviparous female fecundity was estimated by counting the number of first-instar larvae produced by individual viviparous females on 2-3 dead oak leaves in the field, dissecting the females near the end of the breeding period, counting the number of embryos in their abdomens, and adding these two numbers; these data ( $21.5 \pm 5.4$ offspring, $N=20$ females) were taken in 1987 (ref. 6 ). In summer, viviparous female fecundity was measured by putting females individually on 2-3 dead oak leaves in nylon bags suspended in the field early in summer, allowing them to breed for about 2 months, and either: (1) counting the number of adult males that were produced by the females that were viviparous (15.0 $\pm 6.7, N=15$, data from 1986), or (2) removing and counting the larvae produced every two weeks for eight weeks (12.2 $\pm 6.9, N=18$, data from 1987) (ref. 6). The value used is the average for 1986 and $1987(13.5 \pm 6.8, N=33)$. The relative survivorship, from the egg stage to the pupal stage, of offspring produced by oviparity is set arbitrarily to 1.0 , and the relative survivorship of offspring produced by viviparity is obtained by multiplying through.

offspring should have higher survivorship ${ }^{14}$. In both generations, the average fecundity of viviparous females was about half that of oviparous females, but the survivorship of the offspring of viviparous females to the pupal stage was 1.4 times higher than that of the offspring of oviparous females in spring and 2.1 times higher in summer (Table 1). The contribution of offspring sex, rather than mode of development, to differences in survivorship is unknown. This hypothesis could be tested more directly using a thrips species, such as Sporothrips amplus, in which one sex (males) is produced by both oviparity and viviparity (unpublished data).

In vertebrates, correlates of viviparity include the presence of maternal care in related oviparous species ${ }^{3,4}$ (which is considered as an alternative adaptation to harsh conditions for eggs ${ }^{15}$ ) and the presence of physical defences such as venom or predatory habits (which are presumed to reduce mortality in females encumbered by embryos ${ }^{4,16}$ ). In $E$. tuberculatus, maternal care is clearly an alternative to viviparity, and females use a potent defensive secretion, juglone, to repel predators such as salticid spiders (Blum et al., unpublished data). Thrips apparently show a complete range of variation in reproductive mode, including fully oviparous, egg-retaining, facultatively viviparous, and fully viviparous species ${ }^{17-19}$. Comparative analysis of the correlates of reproductive mode among thrips, coupled with experimental analysis of facultatively viviparous species, should elucidate the selective pressures associated with the two modes of reproduction. Moreover, the presence of facultative viviparity in this taxon suggests that viviparity sometimes originates as a facultative alternative in an otherwise oviparous population, rather than by population-wide directional selection for egg retention.

I thank R. D. Alexander, D. G. Blackburn, R. Crozier, W. D. Hamilton, R. Nussbaum, J. Seget and L. Vawter for helpful comments, and R. Nussbaum for permission to work at the E. S. George Reserve.

\section{Received 12 August; accepted 21 November 1988.}

Blackburn, D. G. thesis, Cornell Univ. (1985).

Blackburn, D. G. Amphibia-Reptilia 6, 259-291 (1985)

3. Tinkle, D. W. \& Gibbons, J. W. Misc. Publs Mus. Zool. Unit. Mich. 154, 1-55 (1977)

4. Shine, R. in Biology of the Reptilia Vol. 15 (eds Gans, C. \& Billett, F.) (Wiley, New York, 1985).

5. Crespi, B. J. Anim. Behav. 34, 1324-1335 (1986).

6. Crespi, B. J. thesis, Univ. Michigan (1987).
7. Crespi, B. J. J. Insect Behav. (in the press)

8. Priesner, H. Z. wien. ent. Ges. 43, 247-249 (1958)

9. Crespi, B. J. Evolution 42, 1199-1211 (1988)

10. Risler, H. \& Kempter, E. Chromosoma 12, 351-361 (1961).

11. Stannard, L. J. Ill. nat. Hist. Surv. Bull. 29, 215-552 (1968).

12. Fisher, R. A. The Genetical Theory of Natural Selection (Oxford University Press, 1930).

13. Seger, J. Nature 301, 59-62 (1983).

14. Williams, G. C. Adaptation and Natural Selection (Princeton University Press, New Jersey, 1966).

5. Blackburn, D. G. \& Evans, H. E. Am. Nat. 128, 165-190 (1986).

16. Shine, R. \& Bull. J. J. Am. Nat. 113, 905-923 (1979).

17. Ananthakrishnan, T. N., Padmanaban, B., Dhileepan, K. \& Suresh, G. Occ. Publs ent. Res. Inst. Loyola College, Madras 5, 1-37 (1984).

18. Haga, K. XVIth Int. Congr. Ent. Kyoto, Japan, Workshop: Conf. Thysanopterists 1-8 (1980),

19. John, O. Ent. Mitteil. 12, 227-232 (1923).

\section{A mutation that changes cell movement and cell fate in the zebrafish embryo}

\author{
Charles B. Kimmel, Donald A. Kane, Charline Walker, \\ Rachel M. Warga \& Mary B. Rothman
}

Institute of Neuroscience, University of Oregon, Eugene, Oregon 97403 , USA

The study of developmental patterning has been facilitated by the availability of mutations that produce changes in cell fate, in animals such as Caenorhabditis elegans ${ }^{1,2}$ and Drosophila melanogaster $^{3,4}$. We now describe a zygotic lethal mutation in the zebrafish, Brachydanio rerio, that also changes how particular embryonic cells develop. Severe pattern deficiencies are observed that are restricted to a single body region, the trunk. The mutation may directly affect mesoderm, as somites do not form in the trunk. Head and tail structures, including tail somites, are relatively undisturbed. The earliest detected expression of the mutation is during gastrulation, when movements of mesodermal cells occur incorrectly. We injected prospective trunk mesodermal cells with lineage tracer dye and observed that in mutants these cells may enter a new body region, the tail, and there may express a new fate appropriate for the changed position.

The mutation, spt-1(b104r1), nicknamed 'spadetail', was initially discovered among the parthenogenetic progeny ${ }^{5}$ of a 